\title{
Erratum to: Genomic origin, expression differentiation and regulation of multiple genes encoding CYP83A1, a key enzyme for core glucosinolate biosynthesis, from the allotetraploid Brassica juncea
}

\author{
Meenu $\cdot$ Rehna Augustine $\cdot$ Manoj Majee $\cdot$ \\ Akshay K. Pradhan $\cdot$ Naveen C. Bisht
}

Published online: 27 November 2014

(c) Springer-Verlag Berlin Heidelberg 2014

\section{Erratum to: Planta}

DOI 10.1007/s00425-014-2205-0

Inadvertently, the grant detail was omitted in the Acknowledgments section of the officially published article. The missing information has now been included and the correct Acknowledgments should read:

Acknowledgments: The central instrumentation, microscopy facility and plant growth facility at NIPGR are highly acknowledged. We thank Mr. Pawan Kumar for performing the divergence time analysis. Technical assistance of Mr. Vinod Kumar is duly acknowledged. This work was supported by project schemes [BT/PR2171/AGR/36/687/ 2011 and Rapid Grant for Young Investigators (RGYI)] of the Department of Biotechnology, India, and the core research grant was from the National Institute of Plant Genome Research, India. The authors declare no conflict of interest exists.

The online version of the original article can be found under doi:10.1007/s00425-014-2205-0.

Meenu $\cdot$ R. Augustine $\cdot$ M. Majee $\cdot$ N. C. Bisht $(\square)$

National Institute of Plant Genome Research, Aruna Asaf Ali

Marg, New Delhi 110067, India

e-mail: ncbisht@nipgr.ac.in

A. K. Pradhan

Department of Genetics, University of Delhi South Campus,

Benito Juarez Marg, New Delhi 110021, India 